\title{
Cenpestao \\ O processo de socialização na construção da identidade dos bibliotecários em Santa Catarina ${ }^{1}$
}

\author{
Daniela Spudeit \\ Mestre; Universidade Federal de Santa Catarina (UFSC), Florianópolis, SC, Brasil; \\ danielaspudeit@gmail.com \\ Miriam Vieira da Cunha \\ Doutora; Universidade Federal de Santa Catarina (UFSC), Florianópolis, SC, Brasil; \\ vieiradacunha.miriam@gmail.com
}

\begin{abstract}
Resumo: Este estudo objetiva analisar o modelo de profissão construído pelos bibliotecários durante o processo de socialização; identificar as formas de inserção desse profissional no mundo do trabalho, o perfil e os motivos que os levaram à escolha da profissão para compreender como a socialização contribui na construção da identidade. A fundamentação teórica para o estudo foi baseada, principalmente, em Hughes (1958), Dubar (2005), Berger e Luckman (2009). Os resultados evidenciaram que o interesse pela profissão foi despertado pelas aptidões, pelo gosto da leitura e pela influência que esses profissionais tiveram de familiares e de amigos que conheciam a profissão. Demonstram que a identidade foi construída por meio das relações pessoais, profissionais e no ambiente de trabalho, o que facilitou a sua inserção profissional. Em relação ao modelo profissional, a pesquisa mostrou que os bibliotecários passam por várias fases, como a imersão na cultura profissional, o choque de realidade entre o modelo ideal e o real para, em seguida, reconstruir seu modelo com base na imagem idealizada e na imagem real de profissão. Conclui-se que a identidade profissional está sempre se construindo, de acordo com as vivências e experiências do meio em que esse profissional está inserido e das mudanças no mundo profissional.
\end{abstract}

Palavras-chave: Identidade Profissional. Socialização Profissional. Bibliotecário. Santa Catarina.

\section{Introdução}

As relações sociais são constantes, caracterizando e transformando as organizações humanas ao longo da história. Ao nascer, o indivíduo ingressa em seus primeiros mundos sociais: a família, a creche, o orfanato e a escola. Além de lhe garantir a sobrevivência, esses ambientes moldam seus valores sociais. Já na fase adulta, os indivíduos estão, constantemente, passando por processos de socialização que trazem expectativas, tensões, realizações, decepções, alegrias, sofrimentos e desafios.

Os estudos sobre a problemática da socialização são abundantes no campo de Sociologia da Educação. A socialização, segundo Dubar:

[...] não é apenas transmissão de valores, normas e regras, mas desenvolvimento de determinada representação do mundo. É um processo 
de identificação, de construção da identidade, ou seja, de pertencimento e de relação. (2005, p. 23).

Socializar-se é assumir seu pertencimento a um grupo, isto é, assumir suas atitudes, a ponto de elas guiarem sua conduta pessoal e profissional. Os estudos desse autor analisam os processos de socialização e a formação das identidades profissionais.

Antes de se identificar com um grupo profissional, o indivíduo tem uma identidade social que é formada na escola. É no processo de entrada na profissão, no início da carreira, que acontece a socialização secundária, ou seja, a aquisição de competências e a inserção do indivíduo em um ambiente social específico. Deste modo, o enfoque desta pesquisa se dá a partir da análise da construção da identidade, baseada no processo de socialização profissional dos bibliotecários formados em Santa Catarina, pela Universidade do Estado de Santa Catarina (UDESC) e pela Universidade Federal de Santa Catarina (UFSC). Sendo assim, essa pesquisa foi fundamentada nos trabalhos de Hughes (1958) e Dubar (2005).

Estudar a identidade do bibliotecário envolve analisar as exigências da qualificação profissional, as tecnologias, as mudanças no mundo do trabalho, as práticas e as competências profissionais, a conjuntura social em que ele está inserido e os fatores que influenciam tal contexto. Cabe enfatizar, que o processo de construção da identidade engloba a formação acadêmica e profissional e as experiências em diferentes contextos e espaços de socialização. Portanto, pensar sobre profissão implica considerar a socialização profissional, um processo que compreende atitudes, crenças e formas de capacitação que resultam na definição da identidade profissional.

Desse modo, o objetivo geral deste estudo é compreender como a socialização contribui para o processo de construção da identidade do bibliotecário. Seus objetivos específicos são: identificar o perfil dos bibliotecários e os motivos que despertaram a escolha da profissão de bibliotecário; identificar as formas de inserção do bibliotecário no mundo do trabalho e verificar o modelo de profissão construído por esses profissionais durante a socialização profisssional.

\section{Os processos de socialização}

Os estudos clássicos da Sociologia apontam dois espaços de socialização tradicional - a família e a escola. Neste processo, a família é responsável pelos 
ensinamentos de caráter privado. A escola, por sua vez, é responsável pela construção de indivíduos morais e eticamente comprometidos com o ideal público. Esses ambientes têm a responsabilidade de forjar a personalidade de um novo sujeito social, segundo Durkheim (1978). A reflexão desse autor é pertinente para compreender as motivações e a ação individual, já que está ligada a um projeto construído por um conjunto de instituições sociais.

Dubar (2005, p. 120) define a socialização como “(...) a imersão dos indivíduos no que denomina 'mundo vivido', ao mesmo tempo 'um universo simbólico e cultural' e um 'saber sobre esse mundo"”. Para esse autor (2005, p. 127), “(...) a socialização secundária pode produzir identidades sociais orientadas para a produção de novas relações suscetíveis de se transformar por meio da ação coletiva". Segundo Berger e Luckmann (2009, p. 173), “(...) o indivíduo não nasce membro da sociedade. Nasce com uma predisposição para a sociabilidade e torna-se membro da sociedade”. As pessoas se assumem perante o mundo, por meio da passagem de três momentos identificados por Berger e Luckmann (2009) como exteriorização, objetivação e interiorização. Nessa passagem, eles estabelecem identificações, nas quais percebem que todos vivem no mesmo ambiente, e que participam do ser do outro. Somente depois desse grau de interiorização, as pessoas tornam-se membros da sociedade.

Esse processo se inicia na socialização primária, que ocorre, inicialmente, por meio da interiorização, da interpretação de acontecimentos objetivos dotados de sentido, isto é, da manifestação de processos subjetivos significativos para o indivíduo. Essa socialização termina quando o conceito de outro é formado na consciência do indivíduo. Nesse momento, ele se torna um membro efetivo da sociedade e cria uma personalidade.

De acordo com Berger e Luckman (2009, p. 184), “essa interiorização da sociedade, da identidade e da realidade nunca está acabada. A socialização primária fornece a estrutura básica do processo de socialização e influencia a formação da socialização secundária". Segundo os mesmos autores, "A socialização secundária é qualquer processo subseqüente que introduz um indivíduo já socializado em novos setores do mundo objetivo de sua sociedade.” (2009, p. 175).

Os saberes profissionais compreendem um vocabulário, um programa formalizado e um universo simbólico que veiculam uma concepção de mundo. Ao contrário dos 
saberes da socialização primária, os saberes profissionais são definidos e construídos com referência a um campo especializado de atividade (DUBAR, 2005). Os saberes ligados ao trabalho, segundo Tardif e Raymond "[...] são construídos progressivamente durante um período de aprendizagem que varia de acordo com cada ocupação, exigindo conhecimentos, competências, aptidões e atitudes específicas." (2000, p. 211).

No campo da socialização profissional, o 'saber fazer' e o 'saber ser' envolvem conhecimentos, competências, habilidades e atitudes profissionais. Saber fazer significa associar a técnica ao conhecimento teórico. O 'saber-ser' engloba a postura ética e autônoma dos indivíduos, visto que as atitudes individuais influenciam a coletividade (SILVA; CUNHA, 2002).

Nesse contexto, 'aprender a fazer' remete à ideia de qualificação e competência. Após concluir o curso de graduação, o profissional precisa estar constantemente buscando oportunidades de atualização. É nessa interação com o meio e com outros, que a socialização interfere na construção da identidade do indivíduo. 'Aprender a ser' direciona para a postura profissional, ou seja, para os valores formados na família, na escola, etc. Estes valores influenciam o indivíduo, sua personalidade, sua postura e suas atitudes evidenciadas na sua atuação, na sua relação com os pares e na sua prática profissional.

O processo de socialização profissional é formado com base na aprendizagem dos valores, interesses, habilidades, conhecimentos, crenças e formas de concepção de mundo, característicos dos membros de uma profissão.

\section{1 A Socialização Profissional}

As teorias sociológicas contribuem para a análise dos processos de formação e socialização profissional. Hughes (1958) analisou esse processo com foco na Medicina. Dubar (2005), a partir da teoria de Hughes, estudou a socialização e a identidade profissional.

A adaptação do indivíduo à cultura de uma organização se dá pelo processo de socialização. Estudada pela Psicologia Social, a socialização abrange a interação do sujeito em uma instituição pela internalização de suas normas, seus valores e suas representações. Além disso, envolve a relação do sujeito com a instituição, no papel de 
estudante ou de aprendiz. Logo, o processo de socialização se prolonga durante todo o período de exercício profissional.

O trabalho modifica a identidade do trabalhador, pois trabalhar não é apenas fazer alguma coisa, mas fazer alguma coisa de si mesmo. A identidade dos indivíduos carrega as marcas da sua atividade e é caracterizada pela sua atuação profissional (TARDIF; RAYMOND, 2000). A formação do profissional inclui o conjunto de disciplinas aprendidas, durante o processo de formação, e o seu novo papel, a partir de uma conversão a uma nova visão de mundo, ou conversão identitária, que consiste em se modificar a partir da incorporação de novas competências profissionais (HUGHES, 1958).

A construção da identidade profissional está, intrinsecamente, relacionada à socialização. Este processo é constituído no momento em que os saberes, os valores, as práticas e os discursos profissionais, desencadeados no exercício de uma ocupação, modelam a identidade profissional dos indivíduos. A socialização é concebida como uma iniciação na cultura profissional e uma conversão do indivíduo a uma nova concepção de si e do mundo, ou seja, o surgimento de uma nova identidade. Esse processo não ocorre de forma linear e passiva, uma vez que considera a história, as expectativas e os projetos profissionais de cada um. (DUBAR, 2005).

Para Tardif e Raymond (2000) e Dubar (2005), os primeiros anos da carreira representam um período de aprendizagem intensa que determina o futuro profissional e a relação com o trabalho. A escolha da profissão não é um fato isolado, é fruto de amadurecimento pessoal, influenciada pelo meio social e pelas representações pessoais.

\subsubsection{A escolha da carreira}

A escolha profissional é fundamentada por fatores contextuais que se modificam conforme a situação, o momento político, o ambiente, as motivações internas, as condições de saúde e financeiras, as aptidões, os interesses, a personalidade, a região, a cultura, os valores, as crenças, o prestígio social, a vocação, o mercado de trabalho, a família, entre outros (LUZ FILHO, 2002). Ainda, Whitaker (1985) enfatiza as frustrações profissionais dos pais, a visão romântica da profissão e as ilusões do mundo do trabalho como fatores que influenciam a escolha profissional. 
Para Soares (1991), o início da carreira é marcado por expectativas e sentimentos, às vezes, contraditórios. O começo desse processo pode significar uma mudança das ideias formadas na universidade, em um momento de descoberta e de aprendizado. Dubar (2005, p. 136) explica que "esse momento caracteriza-se por uma imersão na cultura profissional". É um momento de confrontação de estereótipos profissionais adquiridos nos diferentes espaços de socialização.

Segundo Schein (1996), a carreira é constituída por várias fases, inicialmente, a profissão é apenas um pensamento, quando o indivíduo inicia seu processo educacional; depois acontece a formação profissional propriamente dita, que varia de acordo com a carreira escolhida; em seguida ocorre o ingresso no mundo do trabalho, quando suas aptidões e valores profissionais são testados em meio às atribulações da vida prática, e por último, ocorre a socialização.

A construção da identidade e a adaptação do indivíduo à cultura de uma organização se dão por meio do processo de socialização. Para Hughes (1958), a cultura profissional é formada por conhecimentos técnico-científicos e por uma visão de mundo particular e específica, que se constitui com base na formação profissional e é incorporada pela aprendizagem. Nesse sentido, esse autor cria um modelo de socialização profissional.

\subsubsection{O modelo de socialização profissional de Hughes}

Hughes (1958) afirma que a cultura profissional é formada por conhecimentos técnicos e científicos, com uma visão de mundo particular e específica. Essa cultura é adquirida mediante um processo de formação, concebido como uma aprendizagem, uma iniciação e uma conversão. $\mathrm{O}$ autor formulou uma teoria para estudar a formação das profissões. Por meio do estudo da Medicina, apresentou um Modelo de Socialização Profissional, como um período de iniciação na cultural profissional e de conversão do indivíduo a uma nova concepção de si e do mundo, ou seja, uma nova identidade. O Modelo da Socialização Profissional de Hughes (1958) caracteriza-se por três fases:

a) "passagem através do espelho" - consiste em olhar o espetáculo do mundo através do espelho, aprender a ver o mundo como em um espelho. Nessa fase, a passagem ocorre pela imersão do indivíduo na cultura profissional: 
o aprendiz começa a perceber as pessoas e o mundo com a visão de um profissional, instaura-se uma crise da cultura do senso comum, incompatível com a cultura profissional.

b) "instalação da dualidade" - nessa fase ocorre a transição, a ruptura e a transposição do 'modelo ideal' para o 'modelo prático': há o choque de realidade ou pela diferença entre o imaginário e o real, uma substituição gradual de imagens estereotipadas. Essa lacuna entre o modelo idealizado e o real é fonte de discussão entre grupos de profissionais, sendo motivo de disputa e conflito.

c) "ajuste da concepção de si" - diz respeito ao abandono dos estereótipos anteriores da profissão e ao momento em que o indivíduo forma sua identidade pela tomada de consciência de suas capacidades físicas, mentais e pessoais, de acordo com o modelo de profissão escolhido. Nesta última etapa, o processo de socialização profissional é caracterizado pela conversão a um novo papel, ou seja, um ajustamento entre o modelo ideal e o modelo da realidade prática (HUGHES, 1958).

Ainda, segundo esse autor, a formação de um profissional inclui um conjunto de conhecimentos apreendidos durante esse processo, e implica em um novo papel e em uma nova visão de mundo. É durante esse processo que ocorre a conversão identitária, ou seja, a formação da identidade profissional (HUGHES, 1958). A formação dessa identidade consiste em mudar a si mesmo a partir da incorporação de novas ideias sobre a natureza do trabalho a ser realizado e da obtenção de competências específicas.

\subsection{Identidade profissional}

A socialização define a forma como o indivíduo se insere numa determinada cultura. A partir daí, forma-se a identidade que define sua história de vida, seus sonhos, suas perspectivas de futuro, suas características de personalidade e seus atributos. A identidade é formada por meio das relações que se estabelecem entre as pessoas que desempenham papéis na vida do indivíduo, como pais, parentes, amigos, professores, entre outros. A identidade de um grupo repousa sobre uma representação social construída, quando esse toma consciência de sua unidade pela diferenciação (DUBAR, 
2005). Para compreender como se forma a identidade, é necessário refletir sobre o surgimento de um grupo profissional, ou como as relações entre seus membros, com o meio em que vivem, sua prática e seu modo de pensar e trabalhar se definem.

Construir a própria identidade é um desafio constante de busca por um equilíbrio entre aquilo que o indivíduo é e o que os outros esperam dele. Entre as múltiplas dimensões da identidade, a dimensão profissional tem uma importância particular porque a profissão condiciona a construção da identidade social. As profissões são produtos sociais em constante construção. É possível compreender o processo de construção da identidade, a partir das mudanças de instituições como a família, a escola e a mídia. Tais instituições podem ser consideradas como instâncias socializadoras que existem numa relação de interdependência, em um espaço de múltiplas relações.

Um dos acontecimentos mais importantes da construção de identidade é a saída do sistema escolar e a confrontação com o mercado de trabalho. (DUBAR, 2005). Segundo esse autor, é dessa primeira confrontação que depende a construção de uma identidade profissional, que não é apenas uma identidade com o trabalho, mas uma projeção de si, a antecipação de uma trajetória de emprego e de uma lógica de formação.

É na formação universitária que se dá a construção identitária. Essa construção também é influenciada pelos sonhos, pelos projetos de vida, pela família, pelos professores e pelos amigos. Segundo Silva e Morigi (2008), a construção da identidade começa a se fortalecer no momento do ingresso na universidade. Pensar em identidade profissional significa analisar as exigências da qualificação, as tecnologias, as mudanças no mundo do trabalho, as práticas e as competências profissionais, bem como, a conjuntura social em que o profissional está inserido e os fatores que influenciam tal contexto.

A profissão de bibliotecário passou por muitas alterações significativas ao longo da história. Este profissional, segundo a Classificação Brasileira de Ocupações (BRASIL, 2003), é um dos profissionais da informação e está classificado com o código 2612, juntamente com o documentalista e o analista de informação.

Desde a criação do curso de Biblioteconomia no Brasil, a profissão sofreu influências internas e externas. O primeiro curso de Biblioteconomia no Brasil foi criado na Biblioteca Nacional, em 1911, inspirado no modelo da École de Chartes 
francesa (MUELLER, 1985). As principais fases do ensino de Biblioteconomia no Brasil, segundo Oliveira (1983), são:

\begin{abstract}
Criação do primeiro curso de Biblioteconomia em 1911, criação de associações profissionais a partir de 1938, legislação profissional em 1962 assegurando o monopólio de seus serviços, elaboração do Código de Ética da Profissão aprovado em 1963 pela FEBAB, elaboração do currículo acadêmico enquadrando a Biblioteconomia em nível de ensino superior em 1962, desenvolvimento de corpo de teoria a partir de 1970 com criação de cursos de pós-graduação, aumento na produção científica especializada em Biblioteconomia através da publicação de periódicos científicos (OLIVEIRA, 1983, p. 4).
\end{abstract}

$\mathrm{Na}$ segunda metade do século $\mathrm{XX}$, ocorreram mudanças na área de Biblioteconomia, influenciadas pelas tecnologias de informação. Entretanto, esse processo não é linear, já que envolve conflitos, ocasionados pelo redimensionamento dos papéis e pela desterritorialização do espaço das unidades de informação. As mudanças organizacionais e sociais modificam a identidade profissional. Novos ambientes são formados, novas exigências são requeridas e o mercado sofre alterações. Essas mudanças refletem-se nas habilidades profissionais, redimensionando sua identidade (SILVA; MORIGI, 2008).

Com a implementação de novas ferramentas de recuperação da informação, o bibliotecário necessita de um aprendizado permanente, para estar apto a transmitir ao usuário informações cada vez mais complexas (PASSOS; SANTOS, 2005). Esse aprendizado ocorre por meio da educação continuada, que garante a competitividade no mundo do trabalho. Além disso, a formação profissional é entendida segundo Martucci (1999, p. 45), "como um processo global e contínuo de construção ao longo da vida, considerando-se a vida como um espaço de educação. Estar em formação é construir uma identidade pessoal e profissional".

Em relação à formação profissional do bibliotecário, Walter e Baptista (2008) afirmam que essa formação deve estar conectada com as mudanças originadas pela introdução de ferramentas tecnológicas de armazenamento e recuperação da informação, a fim de que esse profissional tenha condições de sobreviver no espaço competitivo do mundo do trabalho.

A prática da profissão caracteriza e define o o campo de atuação, conferindo aos seus praticantes uma identidade (SILVA; GOMES, 2008). Estudos como o de Baptista e Mueller (2004), indicam que os bibliotecários estão ganhando destaque devido à 
necessidade de organizar e difundir informações. Isso contribui para a inserção do profissional no mundo do trabalho, de acordo com Loureiro e Jannuzzi (2005). Esses autores analisaram a inserção desses profissionais no mercado de trabalho. Observaram também, fatores como a ampliação e diversidade dos espaços de atuação, a intensificação da fiscalização pelos conselhos da área e o desenvolvimento de um trabalho de conscientização dos empregadores em relação aos serviços prestados, dentre outros.

As mudanças na atuação profissional contribuem para a formação da autoimagem do bibliotecário, segundo Oliveira (1980). Os estudos sobre a autoimagem e as representações sociais do bibliotecário, de Oliveira (1980), Passos e Santos (2005), Barbalho (2005), Walter e Baptista (2008), Silva e Gomes (2008), Silva (2009), Silva e Gomes (2010) analisaram a representação desse profissional no imaginário social.

As pesquisas de Oliveira (1980), Silva e Gomes (2008) focalizam a autoimagem do bibliotecário baseando-se em fatores como remuneração, condições de trabalho, status profissional, estereótipo, consciência social, requisitos intelectuais e mecânicos. Segundo essas autoras, o estereótipo profissional, o fazer cotidiano, a satisfação profissional, a formação acadêmica e a educação continuada interferem na autoimagem do bibliotecário.

A pesquisa de Silva e Morigi (2008), com dirigentes da classe de Biblioteconomia no Brasil, analisou suas representações sociais na construção da identidade e suas práticas. Os autores constataram que os dirigentes percebem a formação de uma identidade voltada à realidade atual, em um mercado de trabalho potencial; uma modernização da área, motivada, principalmente, pela atualização e pelas mudanças dos currículos dos cursos de Biblioteconomia.

A construção identitária do indivíduo acontece e se fortalece na formação universitária, a partir do convívio com pessoas que almejam atuar na mesma área (SILVA; MORIGI, 2008). Segundo os autores, a mudança dos perfis e da representação social dos bibliotecários vem modificando a sua prática profissional e sua autoestima.

Com base nessas pesquisas, observa-se que a prática profissional do bibliotecário é transformada de acordo com as expectativas da sociedade, comprovando as influências do meio. 
Para Silva e Morigi, "O processo de mudança das práticas dos bibliotecários vem ocorrendo, através do ensino de Biblioteconomia. As alterações das estruturas curriculares introduzem inovações para a adequação às novas exigências do mercado." (2008, p. 11).

A pesquisa de Walter (2008) teve como foco a construção da imagem do bibliotecário. O estudo analisou o mercado de trabalho, as competências profissionais e as condutas (éticas e morais), a partir da opinião de bibliotecários e docentes. Além disso, a pesquisa objetivou identificar os valores e crenças dos bibliotecários; analisar as práticas da profissão mais destacadas pelos bibliotecários, pelos docentes e pela literatura da área e verificar os fatores que representam a imagem profissional. Esse estudo mostrou uma visão positiva da profissão: $87 \%$ alegaram ter orgulho de ser bibliotecário, aconselhariam outras pessoas a seguir a carreira e não mudariam de profissão, ao contrário de pesquisas anteriores,

De acordo com Silva e Gomes (2010), são fatores formadores da autoimagem: a formação acadêmica, as demandas da sociedade decorrentes das suas mudanças históricas e a redefinição do perfil profissional, mais voltada ao atendimento das necessidades sociais. Tal formação influencia e é influenciada pelo fazer profissional, que trabalha com carências de recursos e de infraestrutura. Além disso, essas mudanças sociais estimulam, segundo as autoras, o bibliotecário a agir no sentido de expandir os horizontes da sua profissão. Isso faz com que esse profissional construa uma consciência dual. Por um lado, ele tem consciência do potencial social do seu fazer profissional; por outro, enfrenta, cotidianamente, os limites impostos pelas barreiras que inibem a realização de suas atividades.

Com base nas pesquisas de Oliveira (1980), Passos e Santos (2005), Loureiro e Januzzi (2005), Walter e Baptista (2008), Silva e Morigi (2008), Silva (2009) e Silva e Gomes (2010), percebe-se que os estereótipos da imagem do bibliotecário no imaginário social e as mudanças dos seus perfis estão relacionados à sua atuação no mundo do trabalho.

Pensar sobre a identidade do bibliotecário significa analisar a conjuntura social em que esse profissional está inserido e os fatores que influenciam tal contexto. Para compreender de que forma a identidade é formada, é necessário refletir sobre como 
surge um grupo, ou como se estabelecem as relações entre seus membros, com o meio em que vivem, e sua prática.

Em Santa Catarina, a formação de bibliotecários começou no século XX, na década de setenta, com a implantação dos Cursos de Biblioteconomia da Universidade Federal de Santa Catarina e da Universidade do Estado de Santa Catarina. Durante a década de setenta, Santa Catarina estava passando por muitas transformações impulsionadas pelo plano de desenvolvimento do governador Colombo Machado Salles (1971-1975). Seu governo fundamentou-se no Projeto Catarinense de Desenvolvimento, transformado em Ação Catarinense de Desenvolvimento. A estratégia desse projeto era a dinamização dos centros urbanos para permitir um desenvolvimento econômico com repercussões sociais (SANTA CATARINA, 2010).

Nessa época, a UFSC fez uma Reforma Universitária, criando centros e departamentos de ensino. Durante os anos de 1976 a 1980, várias unidades foram criadas, como a Biblioteca e o Hospital Universitário. Além disso, foram implantados dezoito cursos de graduação, dentre eles, o de Biblioteconomia em 1973 (UFSC, 2005).

O currículo do curso de Biblioteconomia da UFSC vem sendo atualizado para acompanhar a evolução da área. O Departamento de Ciência da Informação, do qual esse curso depende, desenvolve atividades de educação continuada desde 1979.

A outra instituição que oferece curso de Biblioteconomia, no estado, é a Universidade do Estado de Santa Catarina (UDESC), criada em 1965, em Florianópolis. O Centro de Ciências Humanas e da Educação (FAED) foi o primeiro centro da UDESC, criado em 1963. O curso de Biblioteconomia recebeu o reconhecimento do Conselho Estadual de Educação (CEE), em 23 de outubro de 1973 (UDESC, 2005).

Professores e alunos, das duas universidades, promovem a organização de eventos de capacitação profissional, têm parcerias com a Associação Catarinense de Bibliotecários e com o Conselho Regional de Biblioteconomia, têm projetos de pesquisa e extensão, etc.

Além das universidades, a Associação Catarinense de Bibliotecários (ACB) promove cursos de educação continuada para profissionais e auxiliares de bibliotecas. A ACB desenvolve suas atividades desde 1975 (ACB, 2010).

A ACB edita a Revista ACB: Biblioteconomia em Santa Catarina, que divulga relatos de experiências profissionais. Esta Associação promove o Painel 
Biblioteconomia em Santa Catarina, desde 1982 - um fórum anual que discute a profissão no estado.

Esta entidade promove anualmente a Semana do Bibliotecário, na qual são discutidos assuntos referentes à profissão. Ainda, promove cursos de curta duração, trazendo para ministrá-los, professores de todo o país (ACB, 2010).

Essas ações da Associação, juntamente com os cursos de Biblioteconomia da UDESC e da UFSC, contribuem para o desenvolvimento da profissão no estado. A partir desse contexto, é possível identificar elementos que permitem compreender como a identidade dos bibliotecários de Santa Catarina é construída e influenciada pelo meio, pela prática e pelas relações entre seus membros.

\section{Análise dos resultados}

Para compreender como ocorreu o processo de construção da identidade dos bibliotecários formados em universidades catarinenses, foi utilizada a técnica de análise de conteúdo de Bardin (2004), que permite inferências para construir as variáveis analisadas de acordo com o contexto da pesquisa, ou seja, possibilita a interpretação controlada do seu conteúdo.

Para fins de pesquisa, 12 bibliotecários aceitaram ser entrevistados. Esses profissionais graduaram-se em 2006, sendo seis na UFSC e seis na UDESC; são registrados no Conselho Regional de Biblioteconomia e estão exercendo a profissão. Os dados foram analisados tendo como parâmetro o Modelo da Socialização Profissional proposto por Hughes (1958), conforme resultados apresentados a seguir.

Nove desses profissionais são mulheres, e três, homens, com idades entre $25 \mathrm{e}$ 40 anos. No que tange à qualificação profissional, observou-se que:

a) dois bibliotecários fizeram mestrado em Ciência da Informação;

b) cinco fizeram cursos de especialização, nas áreas de Arquivologia e Biblioteconomia- com foco em Gestão Documental, Formação de Leitores e Gestão de Bibliotecas Escolares;

c) cinco bibliotecários não fizeram nenhuma formação complementar.

d) Com referência ao local de atuação: 
e) cinco bibliotecários trabalham em bibliotecas universitárias privadas;

f) dois profissionais estão atuando como autônomos, prestando serviços na área de normalização e gestão documental;

g) um bibliotecário atua em empresa pública;

h) dois bibliotecários trabalham em instituições de ensino na área de gestão documental;

i) um bibliotecário atua em uma biblioteca de escritório de advocacia;

j) um bibliotecário trabalha em uma biblioteca escolar e universitária.

Nove profissionais atuaram em mais de um lugar após a conclusão da graduação.

Com o objetivo de conhecer os motivos que influenciaram o bibliotecário na escolha da profissão, questionou-se sobre o que despertou o interesse pela Biblioteconomia. Os entrevistados que se formaram na UDESC, mencionaram o gosto pela leitura, pelos livros e pela informação como fatores que despertaram o interesse pela profissão. Percebeu-se que a maioria não conhecia a profissão no momento de fazer sua escolha.

Além do poder simbólico representado pelo diploma universitário, ao escolher uma carreira, outros fatores influenciam a escolha da profissão e despertam o interesse por uma carreira, como os hábitos e as aptidões, assim como o gosto pela informação, pelos livros, pela internet, pela leitura e pelas bibliotecas - fator comprovado por meio dos depoimentos dos entrevistados. Isso mostra que a escolha da profissão é influenciada por interesses, aptidões, características de personalidade e oportunidades (WHITAKER, 1985). Na mesma linha, Luz Filho (2002) enfatiza que os fatores que influenciam a escolha podem modificar-se, conforme a situação, o ambiente, as motivações internas, a vocação e o mercado de trabalho. Um exemplo disso pode ser visto no depoimento a seguir:

\footnotetext{
Depois que passei no vestibular, entrei, mas não sabia muito bem o que era, durante o curso é que fui me apaixonando pela profissão, fui gostando bastante e hoje gosto do que faço, sou apaixonada pela profissão (UDESC3).
}

Um dos entrevistados formados pela UDESC afirmou que conhecia a profissão porque teve contato com profissionais da área que influenciaram sua escolha. Até o momento da escolha profissional, percorrem-se vários caminhos. Segundo Passos e Santos (2005, p. 16) "a família representa um dos ambientes mais importantes, pois é 
por meio dela que se constrói a primeira visão de mundo, com base nos valores adquiridos nesse ambiente".

A influência do meio e de outros profissionais pode também ser verificada nos depoimentos dos entrevistados formados pela UFSC. Percebe-se que o interesse pela profissão foi despertado por incentivo de familiares formados em Biblioteconomia. Conforme Soares (1987), a profissão dos pais influencia, de forma decisiva, a maneira de ver o mundo e a identidade profissional.

Ao analisar as respostas dos sujeitos entrevistados, observa-se que os bibliotecários formados pela UDESC escolheram o curso de Biblioteconomia a partir de interesses, aptidões e características da própria personalidade. Já os formados pela UFSC tiveram influência dos familiares e de outros bibliotecários, como pode ser observado nos depoimentos.

Infere-se que os indivíduos que optam por cursar Biblioteconomia na UDESC possuem mais habilidades e afinidades relacionadas ao perfil do bibliotecário. Já os formados pela UFSC têm mais conhecimento acerca do fazer bibliotecário, pelas relações com outros profissionais.

Nos depoimentos a seguir, é possível verificar que o conhecimento sobre a profissão aconteceu antes da formação:

\footnotetext{
Já trabalhava em biblioteca e senti necessidade de aperfeiçoar os conhecimentos para ajudar no trabalho, amo trabalhar nisto. Já conhecia a profissão antes de atuar, só não fiz o curso antes porque era longe da minha cidade (UFSC3).

Fui trabalhar numa biblioteca universitária como auxiliar de biblioteca e ao conhecer mais a rotina da biblioteca e a bibliotecária chefe, que é uma pessoa e profissional exemplar, passei a gostar mais ainda desta profissão (UDESC4).
}

Estes depoimentos reafirmam a relação entre a escolha profissional e as demandas do mundo do trabalho. Segundo Luz Filho "[...] fatores como o status, a vocação, o mercado de trabalho e o prestígio social contribuem na escolha da carreira." (2002, p. 31). Whitaker afirma que “[...] os psicólogos apontam aptidões, interesses, características de personalidades, atitudes, valores, oportunidades educacionais dadas pelo nível sócio-econômico como fatores que atuam sobre o indivíduo na escolha profissional." (1985, p. 43). 
Os sujeitos pesquisados têm características comuns, como o gosto pela leitura e a influência do meio e de outros profissionais. Mesmo não conhecendo a profissão, tais fatores despertaram nos entrevistados, de ambas as universidades, o interesse pela carreira. Percebeu-se nos depoimentos, que a influência do mundo do trabalho, dos familiares e do meio foi fundamental.

A pergunta sobre a inserção no mercado de trabalho buscou identificar as formas de ingresso e compreender como ele ocorreu. A maioria dos formados pela UDESC distribuiu currículos, acompanhou a divulgação de vagas e processos seletivos. Porém, a indicação de colegas foi o principal meio de inserção no mundo do trabalho.

Entre os profissionais formados pela UFSC que responderam a pesquisa, muitos já trabalhavam antes de concluir a graduação. Outros, assim que se graduaram, conseguiram uma oportunidade de trabalho por meio de processo seletivo

As entidades de classe e os cursos de Biblioteconomia possibilitam a aquisição de competências específicas na área de atuação dos profissionais. Nessas instituições, ocorrem discussões sobre a profissão em Santa Catarina, assim como conflitos que permeiam as relações entre esses mundos.

No início da carreira, o contato com professores, colegas e outros profissionais é, em geral, intenso, facilitando a sua indicação para vagas de trabalho. Isso é observado nos entrevistados formados pela UFSC:

Foi através dos estágios e dos projetos dentro da faculdade. Neste trabalho que estou atualmente consegui através da indicação de outro profissional que me conhecia e conhecia meu trabalho, participei do processo seletivo, fiz a entrevista e fui chamado para a vaga (UFSC1).

Depois de formado eu sabia que uma hora ou outra tinha que enfrentar o mercado de trabalho, uma amiga que sabia que eu estudava isto me indicou para uma empresa (UFSC6).

Em relação à cultura local, os depoimentos mostram que os profissionais formados em Santa Catarina participaram de cursos e eventos; percebe-se que esses contatos contribuíram para a indicação para postos de trabalho. Esses contatos são mais freqüentes no início da carreira, marcada por expectativas à medida que o profissional se insere no mundo do trabalho e se depara com situações de descobertas e aprendizados constantes. Segundo Dubar, “[...] este momento se caracteriza por ser uma imersão na cultura profissional que aparece brutalmente como o inverso da cultura profana e coloca 
a angustiante questão da forma como as duas culturas interagem no interior do indivíduo." (2005, p. 136).

Ao entrevistar os profissionais das duas universidades sobre a primeira oportunidade de trabalho deles, percebeu-se que sentimentos contraditórios permeavam as suas respostas, tais como angústia, preocupação com a situação financeira, desânimo, frustração, insegurança e medo; demonstrando as tensões e os conflitos nos diferentes espaços de socialização conforme descrito a seguir.

Eu queria terminar a faculdade e me inserir no mercado, trabalhar na área, poder estar preparado para atuar na área, a gente fica com medo por ser o primeiro, depois que a gente começa e vê que tem o apoio de outros profissionais (UFSC1).

Quando me formei, distribui vários currículos na cidade e desanimei pois não tinha retorno, percebi que em Florianópolis era difícil para conseguir emprego, ainda mais quando não se tem experiência, estava desanimada, mas sempre busquei, eu tinha como ponto de vista que no interior sempre tem mais oportunidade e eu nunca desisti, tinha esperanças de conseguir, vi que era difícil conseguir trabalho na área, principalmente na capital (UDESC3).

Em outros depoimentos, é possível perceber, nos entrevistados, o desafio ao iniciar uma carreira, o medo do novo e a vontade de colocar em prática os conhecimentos adquiridos. Observa-se que as ideias dos modelos real e ideal da profissão evidenciam-se nos diferentes depoimentos. Isso quer dizer que as visões da prática profissional são, muitas vezes, contraditórias e demonstram os conflitos existentes nos espaços de socialização, mostrando que a construção da identidade profissional não é linear, conforme é enfatizado por Dubar (2005).

Tais sentimentos provocam crises e tensões, características da formação da identidade profissional que acompanham os sujeitos em toda sua trajetória. As tensões entre o modelo profissional idealizado e o real produzem sentimentos de desencantamento. Em outros momentos, ocorre um novo encantamento pela profissão. Dessa forma, a identidade profissional é, constantemente, reconstruída.

Durante a graduação, os estudantes criam modelos profissionais idealizados pela vivência em sala de aula. Quando o indivíduo se insere no mundo do trabalho, a percepção da profissão vai se moldando conforme a realidade do seu local de atuação. Dessa forma, tal processo de socialização vai se alterando durante a trajetória profissional e é parte da formação da identidade do indivíduo. 
É interessante observar que a visão do fazer profissional está relacionada ao local de atuação e às interações que acontecem durante o período de socialização. Conforme visto nos depoimentos acima, quando questionados sobre o modelo de bibliotecário, essa referência está relacionada a diferentes funções, que variam conforme as relações e o ambiente profissional.

Em alguns depoimentos, observa-se que os entrevistados, por desconhecer a profissão, acreditavam que qualquer profissional que atuava em biblioteca era bibliotecário. Fica evidente a forte relação que existe entre o espaço físico da biblioteca e o bibliotecário. Mesmo sabendo que existem outros espaços de atuação relacionados à gestão da informação, quando vão atuar no mercado de trabalho, o espaço da biblioteca é a identificação mais forte do bibliotecário.

A formação de uma nova identidade consiste em mudar a si mesmo, a partir da incorporação de novas ideias sobre a natureza do trabalho e da aquisição de competências específicas para o desempenho da carreira. A construção dessa identidade é considerada, segundo Hughes (1958), a base do processo de socialização profissional.

Nas entrevistas, observou-se que algumas pessoas tinham um modelo profissional, por ter familiares ou amigos bibliotecários, ou por ter tido contato na infância com profissionais que atuavam em bibliotecas escolares.

Segundo Hughes (1958), a cultura profissional é formada pelos conhecimentos técnico-científicos e por uma visão de mundo particular, formada a partir de um processo. A idealização de um modelo profissional é resultado dessa visão. A cultura é adquirida por intermédio da formação profissional e incorporada por meio da aprendizagem.

A primeira fase do Modelo da Socialização Profissional de Hughes é, como explicitado acima, a passagem através do espelho. Esta passagem ocorre através da imersão do indivíduo na cultura profissional. Em geral, nesse momento, se instaura uma crise da cultura do senso comum, incompatível com a cultura profissional. Essa descoberta da realidade do mundo profissional pode, algumas vezes, ser traumatizante, conforme depoimentos a seguir:

Quando me formei, tinha muita vontade de trabalhar em biblioteca, mas foi frustrante, [...], desestimulante, fui atuar numa biblioteca escolar, mas hoje não voltaria nem que passasse por dificuldades financeiras. Atualmente trabalho com informação jurídica, gestão 
documental num escritório de advocacia e hoje sim me sinto realizada (UDESC5).

Depois de formado em 2006 eu sabia que uma hora ou outra tinha que enfrentar o mercado de trabalho, [...] fui em busca de conhecimento, fui atrás dos amigos que estavam trabalhando na área, não tinha muita experiência, mas tinha muita vontade, esta primeira experiência foi gratificante (UFSC6).

Na segunda fase do Modelo de Hughes, denominada 'instalação da dualidade', ocorre a transição entre o modelo ideal e o real. Nessa fase, o indivíduo forma uma imagem, uma identidade com base em um grupo de referência, a partir da interação com outros sujeitos. O depoimento a seguir mostra a segunda etapa da socialização profissional de Hughes (1958):

\begin{abstract}
Não tenho um modelo profissional, mas até a metade da graduação eu ainda tinha este modelo daquela bibliotecária da minha cidade muito vivo e queria que todos meus colegas fossem iguais a ela, vi que não era bem assim, a maioria estava ali porque tinha caído de pára-quedas, por que não tinha outra opção no vestibular, que queria apenas um diploma. Aí o máximo que eu consegui foi eu ser como ela, pois meus colegas não gostavam muito da profissão e eu achava que eles tinham que gostar de ler e na realidade não se mostrou bem assim(UFSC5).
\end{abstract}

Percebe-se a dualidade entre o real e o ideal, e também o conflito entre o que foi aprendido - o saber - e a realidade da profissão - o fazer. O real é formado pela rotina, pela aplicação da teoria, pelos desafios, pelas dificuldades e pelos receios de enfrentar situações novas, momentos de dúvida, assim como, pelas relações de trabalho que geram expectativas, escolhas, responsabilidades e rupturas. Em muitas unidades de informação, a realidade é diferente da vivenciada na universidade. Muitas unidades não têm computador nem recursos para aquisição de equipamentos ou assinatura de documentos eletrônicos.

O mundo do trabalho exige competências e habilidades como: saber ser, saber conviver, saber fazer e saber aprender (DELORS et al, 2010). O mercado reivindica profissionais autônomos, empreendedores, articulados politicamente. Além disso, é importante que eles saibam desenvolver projetos, captar recursos e gerenciar. Portanto, cabe ao profissional buscar esses conhecimentos e complementar sua formação constantemente. Outro exemplo relativo ao fazer profissional, diz respeito aos investimentos que a unidade recebe da instituição à qual é subordinada. Aprende-se durante o curso a fazer a gestão de acervo, a aquisição e o desenvolvimento das 
coleções. No entanto, as instituições nem sempre destinam verbas para a atualização do acervo. Em muitas instituições, existe apenas um bibliotecário para fazer todo o trabalho técnico e o atendimento aos usuários.

Nesse momento de transição entre o modelo ideal e o real, pode ocorrer a substituição gradual de imagens estereotipadas, e assim, começa a se formar um novo modelo, ou seja, a identidade profissional vai se construindo a partir da aquisição de valores, normas e modelos de comportamento dos membros de um grupo.

$\mathrm{Na}$ terceira fase do modelo de Hughes (1958), ocorre o ajustamento entre o modelo ideal e o real. Esse ajustamento significa o abandono dos estereótipos da profissão. É o momento em que o indivíduo constitui sua identidade, pela tomada de consciência de suas capacidades. No depoimento a seguir, percebe-se esta fase:

\footnotetext{
Eu tinha um modelo sim, durante a minha vida escolar freqüentei bibliotecas e era muito incentivada para a leitura, apesar de que nestas bibliotecas que eu freqüentava não havia bibliotecários, e sim professores readaptados. Quando eu entrei na faculdade eu idealizava um modelo de um profissional proativo e comprometido em realizar um trabalho de qualidade e com excelência, mas não encontrei nenhum profissional da forma que eu idealizava. Quando me formei fui em busca deste modelo de bibliotecário que eu queria ser, comprometido e proativo, era isto que eu buscava e idealizava para mim como modelo profissional (UDESC5).
}

Os depoimentos dos profissionais evidenciaram a lacuna entre a teoria e a prática. Quando o profissional se insere no mundo do trabalho, percebe que nem tudo o que aprendeu poderá ser colocado em prática. A partir desse momento, o profissional começa a traçar estratégias para melhorar sua atuação, como citou um dos entrevistados quando mencionou o problema da visibilidade da profissão.

Cabe enfatizar que, algumas vezes, o desenvolvimento profissional não acontece como preconizado no modelo de Hughes, já que a realidade está sendo, permanentemente, modificada, provocando transformações no mundo do trabalho. As mudanças dos papéis e dos valores profissionais são uma decorrência natural num mundo no qual as transformações tecnológicas alteraram o fazer bibliotecário, ampliando a quebra de fronteiras e paradigmas da profissão (WALTER, 2008).

A força dos estereótipos na construção da imagem do bibliotecário impacta sua identidade. Segundo Walter e Baptista (2008, p. 31), “A preocupação com a visão sobre os profissionais é importante, pois os empregadores percebem o quanto a profissão é 
valorizada socialmente.". Nos depoimentos abaixo, observam-se imagens relacionadas ao estereótipo profissional:

Tinha sim, pois meu primeiro contato foi minha irmã [que era bibliotecária], ela que me falou do curso e fui conhecendo a profissão, eu conversava com ela e ela falava das atividades, ela falava do bibliotecário que quebrava aqueles estereótipos, que hoje o profissional era mais moderno (UFSC1).

Durante a faculdade sempre se falava muito no profissional defasado, enfatizando os estereótipos negativos, que este profissional precisava mudar sua imagem e buscar esta valorização (UDESC5).

A imagem do bibliotecário sofre influência do estereótipo veiculado em filmes, livros, telenovelas e comerciais, e influencia, segundo Silva (2009), a visibilidade da profissão. Assim como ocorre em outras profissões, os bibliotecários possuem uma imagem ligada ao seu comportamento. Nos depoimentos a seguir, questionam-se a imagem e o modelo de bibliotecário.

Eu vejo que a Biblioteconomia é um curso que tem pouco Ibope, não é comentado na mídia, nos meios de comunicação, pelos alunos que fazem vestibular, o espaço dado ao profissional na mídia é pouco. Por mais que se fale, no modelo novo de profissional, de biblioteca, por mais que se fale nas mudanças, sempre cai em biblioteca e livros, as pessoas não conhecem ainda a profissão e a biblioteca, um centro de informação, um arquivo, etc.(UFSC1).

Muitas pessoas têm uma visão negativa de bibliotecário que é ranzinza e chato, de óculos, que não quer que mexa no livro. (UFSC3).

Nesses depoimentos, percebe-se que os estereótipos, frequentemente, são relacionados à ideias negativas. Essa associação, mesmo quando compreendida sob seus aspectos positivos, como a mediação e a facilidade de comunicação, é limitante para uma profissão que luta por espaços de trabalho, pelo reconhecimento social e pela modernização de sua imagem (WALTER; BAPTISTA, 2008).

O modelo reproduzido nos meios de comunicação manifesta a imagem presente no imaginário social. De acordo com Barbalho e Rozados (2008, p. 3), "Cada vez que a imagem é veiculada, reforça a visão internalizada, positiva ou pejorativa, constituindo o núcleo principal da formação dos estereótipos.”. Com base na compreensão da sua missão, o bibliotecário pode trabalhar sua autoimagem, contribuindo para a construção de uma identidade positiva, associada a uma maior visibilidade na sociedade (SILVA, 2009). 
Tudo indica que a imagem de guardião do conhecimento, do controle da ordem e do silêncio e da disciplina, está relacionada às tarefas do bibliotecário, conforme visto nos depoimentos. Contudo, estes profissionais estão mudando seu comportamento.

Em algumas entrevistas, percebe-se que alguns deles, antes de entrar na universidade, não sabiam o que era a profissão; por isso não tinham um modelo ideal. Outros repetiam o que ouviam falar devido à convivência com amigos e familiares formados em Biblioteconomia. Observa-se que os entrevistados de ambas as universidades tinham uma concepção formada da profissão e, ao longo da graduação, foram construindo o seu modelo. A seguir, são apresentados depoimentos sobre a mudança do modelo profissional:

Antes eu não conhecia, mas hoje eu vejo o bibliotecário como um profissional que precisa estar em constante atualização e que está exercendo a profissão efetivamente, atuando, praticando principalmente se atualizando, pois antes as pessoas faziam o curso, mas não atuavam, queriam só mesmo um diploma, hoje é diferente. Creio que o modelo de bibliotecário hoje mudou por conta disto, tem que buscar um diferencial, algo a mais que vai diferenciá-lo no mercado, interagir com novas tecnologias, ligados com as práticas de gestão (UFSC1).

Mudou bastante porque durante a faculdade idealizei um perfil de profissional e quando me formei fui em busca disto. No trabalho que estou atualmente consegui atingir este objetivo, isto que faz a gente mudar a realidade do profissional, da nossa profissão e mostrar que é tudo que é possível o bibliotecário fazer, podemos acreditar que é possível uma visão positiva da nossa profissão, temos que acreditar em nós mesmos enquanto profissionais e na nossa profissão (UDESC5).

Nessas respostas, percebe-se a mudança de modelo profissional. Alguns criaram um modelo; outros incorporaram modelos durante a graduação. Outros, por sua vez, modificaram seu modelo com base nas suas experiências, na prática profissional e nas relações com outros profissionais.

Eu incorporei estas referencias, mas acabei aprendendo outras aptidões e quando a gente entra na faculdade você entra de uma forma e sai de outra, eu tenho um modelo hoje diferente de quando entrei na faculdade, abriu um leque maior, o que ele faz, onde ele pode atuar o papel social do bibliotecário, etc. (UDESC4).

Acho que dentro desta visão do bibliotecário mais atuante posso dizer que hoje incorporei este modelo, depois do curso e depois de conhecer a profissão, posso dizer que me espelhei numa pessoa [que era bibliotecária], que admiro muito, foi referência para mim, que se dedica a profissão, que é muito competente, muito correta, que me 
ensinou muito da profissão durante o estágio, muito profissional e que para mim é um exemplo de modelo ideal de profissional (UDESC3).

A formação dessa nova identidade é feita por meio da incorporação de novas ideias sobre a natureza do trabalho a ser realizado e da aquisição de competências específicas. A partir desses depoimentos, percebe-se que para se profissionalizar, o indivíduo passa por um longo período de formação que consiste em transformar-se e incorporar um conjunto de valores e concepções desse novo papel. Novos modelos são criados mediante a interação com outros profissionais no ambiente de trabalho, mostrando a incorporação do indivíduo à cultura de uma organização por meio do processo de socialização. Essa situação provoca um compartilhamento de crenças, valores e hábitos, que irão orientar suas ações dentro de um contexto, definindo, assim, sua identidade. É necessário, segundo Fernandes e Zanelli (2006), que o indivíduo construa uma identidade que o leve a criar uma imagem de si, e os papéis que representa em diferentes momentos da sua experiência social.

A socialização profissional tem como referência a inserção em uma profissão, abrangendo a interação do sujeito com várias instituições pela internalização de normas, valores e representações. Esse processo se prolonga durante todo o período de exercício profissional.

Visando compreender como a socialização contribui no processo de construção da identidade do bibliotecário, as entrevistas permitiram identificar o perfil dos bibliotecários, os motivos que despertaram o interesse pela profissão, as formas de inserção profissional e os modelos de profissão construídos durante a socialização profissional. Verificam-se, em alguns depoimentos, as fases de construção da identidade e do modelo profissional. Cabe enfatizar que o modelo de socialização de Hughes não é linear, estático e permanente. Percebeu-se, nesta pesquisa, que a construção da identidade, por meio da socialização, é dinâmica e, muitas vezes, não acontece a partir de um modelo pré-definido.

O modelo de Hughes serviu como parâmetro para a análise. Contudo, na construção da identidade ele pode não acontecer, já que a realidade está sendo, permanentemente, modificada. É possível verificar que alguns profissionais entrevistados passaram pela fase do ajuste da concepção de si, sem ter passado por um choque de realidade ou pela 'passagem através do espelho'. 
A identidade profissional constitui uma tentativa de explicação do conceito de si, sendo fruto de uma construção psicossocial. Embora a construção da identidade seja progressiva, ela se confirma ou se modifica nas interações que os indivíduos estabelecem e nas experiências vividas, conforme visto nos depoimentos dessa pesquisa.

\section{Considerações finais}

Os resultados evidenciaram que a escolha profissional é determinada pelas influências recebidas pelos profissionais entrevistados, de acordo com o meio em que estão inseridos. Essa escolha afeta a formação da identidade, construída por meio da prática profissional, na interação com colegas de profissão, na relação com outras profissões, no ambiente de trabalho, na participação em eventos e pela influência de familiares e amigos.

Dentre os motivos que despertaram o interesse pela profissão, identificou-se que essa escolha é feita com base nas aptidões, na motivação e no mercado de trabalho. Em relação a influência, percebeu-se que gosto pela leitura, por livros, pela informação e a relação com outros profissionais foram fatores motivadores relatados pelos entrevistados.

A indicação de colegas foi relatada como a principal forma de inserção no mercado de trabalho. Constatou-se que as redes de relacionamento dos profissionais são importantes para a formação da identidade do bibliotecário, principalmente nos primeiros anos da carreira.

O início da carreira é marcado por uma visão da profissão e por uma busca de oportunidades no mercado de trabalho, por meio das relações que o indivíduo estabeleceu anteriormente, em estágios e com outros profissionais. Após o primeiro emprego, essa visão começa a se moldar de acordo com a realidade onde esse profissional se inseriu, influenciada por sentimentos e percepções contraditórios.

O local de atuação profissional é resultado de um conjunto de ações e escolhas profissionais e se relaciona com suas aspirações, sua formação acadêmica, seu perfil, suas habilidades e suas competências. Na graduação, o bibliotecário aprende a 


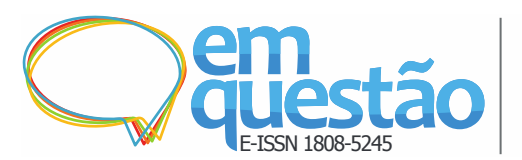

O processo de socialização na construção da identidade dos

bibliotecários em Santa Catarina

Daniela Spudeit, Miriam Vieira da Cunha

representar a informação e a criar mecanismos para recuperá-la. Porém a formação é, continuamente, construída e direciona a carreira a atuação do bibliotecário.

É importante compreender que a identidade profissional está diretamente relacionada à socialização, acompanhando as mudanças da realidade. Evidenciaram-se também, nessa pesquisa, os conflitos entre os modelos ideal e real da profissão nos espaços de socialização. Nesse sentido, a construção da identidade profissional não é linear, uma vez que ela é construída durante a carreira.

As instituições como as associações e as universidades são responsáveis pela socialização dos profissionais. Nessas instituições, ocorrem discussões relativas à profissão em Santa Catarina, assim como, conflitos que permeiam essas relações.

No que se refere às percepções acerca do modelo profissional, foi possível identificar as etapas do modelo de socialização profissional proposto por Hughes (1958). Além disso, ficou evidente que a construção da identidade ultrapassa esse modelo. Na verdade, a realidade está sendo, permanentemente, modificada, acontecendo de forma dinâmica. Observou-se nesta pesquisa que o sujeito se reconstrói, constantemente, durante sua trajetória profissional.

Foi possível compreender como os bibliotecários entrevistados constroem sua identidade profissional com base no contexto em que atuam e com base nas suas relações. Apesar das transformações do mundo do trabalho, este estudo evidenciou que o modelo profissional presente no imaginário dos bibliotecários é, fortemente, relacionado ao seu local de atuação, sendo, na maioria dos casos, restrito às bibliotecas.

As mudanças na atuação e no espaço profissional contribuem para a formação de um modelo de bibliotecário transformado pela prática, pelas necessidades e pelas expectativas da sociedade, comprovando as influências do meio.

Nesse cenário, com a importância crescente da informação mediada pelas tecnologias, foi possível compreender como a socialização contribui para o processo de construção da identidade do bibliotecário, a partir das exigências do mundo de trabalho, fazendo esse profissional redimensionar, constantemente, sua identidade.

\section{Referências}

ASSOCIAÇÃO CATARINENSE DE BIBLIOTECÁRIOS. História da ACB. 2010. Disponível em: 〈http://www.acbsc.org.br/site〉. Acesso em: 12 dez. 2015. 
BAPTISTA, Sofia Galvão; MUELLER, Suzana Pinheiro Machado (Org.). Profissional da informação: o espaço de trabalho. Brasília: Thesaurus, 2004.

BARBALHO, Célia Regina Simonetti.. Regimes de visibilidade das práticas do profissional bibliotecário. In: ENCONTRO NACIONAL DE PESQUISA EM CIÊNCIA DA INFORMAÇÃO (ENANCIB), 6., 2005, Florianópolis, SC. Anais eletrônicos... Florianópolis, 2005. Disponível em:

<http://enancib.ibict.br/index.php/enancib/vienancib/paper/viewFile/1811/952>. Acesso em: 4 jun. 2016.

BARBALHO, Célia Regina Simonetti ; ROZADOS, H. B. F. Perfil do Profissional Bibliotecário Brasileiro: o olhar do Sistema CFB/CRBs. In: SEMINÁRIO NACIONAL DE BIBLIOTECAS UNIVERSITÁRIAS (SNBU), 15, 2008, São Paulo, SP. Anais eletrônico... Disponível em:

<http://www.sbu.unicamp.br/snbu2008/anais/site/pdfs/2876.pdf>. Acesso em: 15 jun. 2016.

BARDIN, Laurence. Análise de conteúdo. Lisboa: Edições 70, 2004.

BERGER, Peter L. ; LUCKMANN, Thomas. A Construção social da realidade: tratado de sociologia do conhecimento. 30. ed. Rio de Janeiro: Vozes, 2009.

BRASIL. Ministério do Trabalho e Emprego. Classificação brasileira de ocupações: CBO 2002. Brasília: MTE, 2003.

DELORS, J. et al (Org). Educação: um tesouro a descobrir. Relatório para a UNESCO da comissão Internacional sobre educação para o século XXI. $6^{\text {a }}$ ed. São Paulo: Cortez; Brasília: UNESCO: MEC, 2010.

DUBAR, Claude. A socialização: construção das identidades sociais e profissionais. São Paulo: Martins Fontes, 2005.

DURKHEIM, Émile. Educação e sociologia. São Paulo: Melhoramentos, 1978.

FERNANDES, Karina Ribeiro; ZANELLI, José Carlos. O processo de construção e reconstrução das identidades dos indivíduos nas organizações. Revista de Administração Contemporânea, Curitiba, v. 10, n. 1, p. 5572, jan./mar. 2006. Disponível em:

$<$ http://www.scielo.br/scielo.php?script=sci_arttext\&pid=S1415-65552006000100004>. Acesso em: 4 jun. 2016.

HUGHES, Everett Cherrington. Men and their work. 2. ed. Glencoe: The Free Press, 1958.

LOUREIRO, Mônica de Fátima; JANNUZZI, Paulo de Martino. Profissional da informação: análise da inserção no mercado de trabalho brasileiro segundo dados do censo demográfico de 2000. In: ENCONTRO NACIONAL DE PESQUISA EM 
CIÊNCIA DA INFORMAÇÃO (ENANCIB), 6., 2005, Florianópolis, SC. Anais... Florianópolis, 2005. 1 CD ROM.

LUZ FILHO, Silvio Serafim da. Escolha profissional: projeto de vida e de carreira. Canoas: Masai, 2002.

MARTUCCI, Elisabeth Márcia. A formação do bibliotecário, os estudos de carreira e a metodologia (auto) biográfica: Campos emergentes de pesquisa. Transinformação, Campinas, v. 11, n. 1, p. 39-46, jan./abr. 1999. Disponível em: <http://www.brapci.ufpr.br/brapci/index.php/article/view/0000000290/80f6678ff60006 8d60a7db4a11906de3>. Acesso em: 4 jun. 2016.

MUELLER, Suzana Pinheiro Machado. O ensino de Biblioteconomia no Brasil. Ciência da Informação, Brasília, v. 14, n. 1, p. 3-15, jan./jun. 1985. Disponível em: <http://revista.ibict.br/ciinf/article/view/222/222>. Acesso em: 4 jun. 2016.

OLIVEIRA, Zita Catarina Prates de. Um estudo da auto-imagem profissional do bibliotecário. 1980. 110 f. Dissertação (Mestrado) - Departamento de Biblioteconomia, Faculdade de Estudos Sociais Aplicados, Universidade de Brasília, Brasília, 1980. Disponível em: 〈http://www.lume.ufrgs.br/handle/10183/1368>. Acesso em: 4 jun. 2016.

OLIVEIRA, Zita Catarina Prates de. O bibliotecário e sua auto-imagem. São Paulo: Pioneira, 1983.

PASSOS, Rosemary; SANTOS, Gildenir Carolino. Formação da identidade profissional do bibliotecário: o desenvolvimento de competência e habilidade na área educacional. In: PASSOS, Rosemary; SANTOS, Gildenir Carolino. (Orgs.). Competência em informação na sociedade da aprendizagem. 2. ed. Bauru: Kayros, 2005. p. 9-28.

SANTA CATARINA. Governo do Estado. Governadores de SC. Florianópolis, 2010. Disponível em:

<http://www.sc.gov.br/conteudo/santacatarina/historia/paginas/governadores.html $>$.

Acesso em: 10 dez. 2015.

SHEIN, Edgar H. Identidade profissional: como ajustar suas inclinações a suas opções de trabalho. São Paulo: Nobel, 1996.

SILVA, Alda Lima da; GOMES, Henriette Ferreira. A auto-imagem do bibliotecário na sociedade da informação: estudo na cidade de Salvador - Bahia. In: ENCONTRO

NACIONAL DE PESQUISA EM CIÊNCIA DA INFORMAÇÃO, 9., 2008, São Paulo, SP. Anais eletrônico... São Paulo, 2008. Disponível em:

<http://enancib.ibict.br/index.php/enancib/ixenancib/paper/viewFile/3082/2208>.

Acesso em: 4 jun. 2016.

SILVA, Alda Lima. A auto-imagem do profissional bibliotecário na sociedade contemporânea: estudo de caso no município de Salvador (BA). 2009. 112 f.

Dissertação (Mestrado em Ciência da Informação) - Instituto de Ciência da Informação, 
Universidade Federal da Bahia, Salvador, 2009. Disponível em:

<https://repositorio.ufba.br/ri/bitstream/ri/7926/1/Dissertacao_completa\%20AldaSilva.p df>. Acesso em: 4 jun. 2016.

SILVA, Edna Lúcia da; CUNHA, Miriam Vieira da. A formação profissional no século XXI: desafios e dilemas. Ciência da Informação, Brasília, v. 31, n. 3, p. 77-82, set./dez. 2002. Disponível em: 〈http://revista.ibict.br/ciinf/article/view/950/987>. Acesso em: 4 jun. 2016.

SILVA, Alda Lima da; GOMES, Henriette Ferreira. O fazer bibliotecário na percepção do profissional na contemporaneidade: um estudo na cidade de Salvador - Bahia. In: ENCONTRO NACIONAL DE PESQUISA EM CIÊNCIA DA INFORMAÇÃO (ENANCIB), 11., 2010, Rio de Janeiro, RJ. Anais eletrônicos... Rio de Janeiro, 2010. Disponível em:

<http://enancib.ibict.br/index.php/enancib/xienancib/paper/viewFile/3522/2647>. Acesso em: 4 jun. 2016.

SILVA, Magali Lippert da; MORIGI, Valdir José. Representações das práticas e da identidade profissional dos bibliotecários no mundo contemporâneo. In: ENCONTRO NACIONAL DE PESQUISA EM CIÊNCIA DA INFORMAÇÃO (ENANCIB), 9., 2008, São Paulo, SP. Anais eletrônicos... São Paulo, 2008. Disponível em: <http://enancib.ibict.br/index.php/enancib/ixenancib/paper/viewFile/3098/2224>. Acesso em: 4 jun. 2016.

SOARES, Dulce Helena Penna. O jovem e a escolha profissional. Porto Alegre: Mercado Aberto, 1987.

SOARES, Dulce Helena Penna. O que é escolha profissional. 2.ed. São Paulo: Brasiliense, 1991.

TARDIF, Maurice; RAYMOND, Danielle. Saberes, tempo e aprendizagem do trabalho no magistério. Educação \& Sociedade, Campinas, ano 21, n. 73, p. 209-244, dez. 2000. Disponível em: 〈http://www.scielo.br/pdf/es/v21n73/4214.pdf >. Acesso em: 4 jun. 2016.

UNIVERSIDADE DO ESTADO DE SANTA CATARINA. Curso de Graduação em Biblioteconomia (Habilitação em Gestão da Informação). Florianópolis, 2010. Disponível em: 〈http://portalfaed.udesc.br/modules.php?name=Conteudo\&pid=12>. Acesso em: 01 dez. 2015.

UNIVERSIDADE FEDERAL DE SANTA CATARINA. Revista UFSC 45 anos. Florianópolis, 2005. Disponível em: $<$ http://antiga.ufsc.br/paginas/downloads/revista_ufsc_45anos_2005.pdf >. Acesso em: 11 dez. 2015.

WALTER, Maria Tereza Machado Teles; BAPTISTA, Sofia Galvão. Formação profissional do bibliotecário. Encontros Bibli, Florianópolis, v. 13, n. 25, p. 84-103, 
2008. Disponível em: <https://periodicos.ufsc.br/index.php/eb/article/view/15182924.2008v13n25p84>. Acesso em: 4 jun. 2016.

WALTER, Maria Tereza Machado Teles. Bibliotecários no Brasil: representações da profissão. 2008. 345 f. Tese (Doutorado em Ciência da Informação) - Departamento de Ciência da Informação e Documentação, Faculdade de Economia, Administração, Contabilidade e Ciência da Informação, Universidade de Brasília, Brasília, 2008. Disponível em:

<http://repositorio.unb.br/bitstream/10482/5288/1/2008\%20Maria\%20Tereza\%20Mach ado\%20Teles\%20Walter.pdf>. Acesso em: 4 jun. 2016.

WHITAKER, Dulce. A escolha da carreira. São Paulo: Moderna, 1985. 


\title{
The socialization process in the identity construction of librarians in Santa Catarina
}

\begin{abstract}
This research aims to analyze the professional model built by the librarians during the socialization process; to identify ways of inserting them in the professional world; their profile and the reasons that led them to choose the profession, in order to understand how the socialization process contributes to their identity construction. The results showed that the interest in the profession was sparked by the aptitudes and the taste for reading. It also showed that these professionals were influenced by family and friends who already knew the profession. The data analysis shows that the identity of these librarians was built by the personal and professional relationships and at the work environment, which facilitates the employability. Regarding the professional model, the research showed that librarians go through various stages, such as the immersion in the professional culture and the shock of reality between the real and the ideal model. After that, they rebuild the professional model based on the idealized image and the real image of the profession. We concluded that professional identity is always being built, according to the experiences of the environment in which the professional is inserted and the changes in their professional world.
\end{abstract}

Keywords: Professional Identity. Professional Socialization. Librarian. Santa Catarina.

Recebido: 02/04/2016

Aceito: $24 / 05 / 2016$

\footnotetext{
${ }^{1}$ Esse artigo é resultado da Dissertação de Mestrado defendida no Departamento de Ciência da Informação (PGCIN) da Universidade Federal de Santa Catarina (UFSC).
} 